Piwulang 8 (1)(2020)
Teaching
http://journal.unnes.ac.id/sju/index.php/piwulang

\title{
PENGEMBANGAN MEDIA PEMBELAJARAN MITUHU (KOMIK PITUTUR LUHUR) PADA KOMPETENSI DASAR MENULIS DIALOG SISWA KELAS VII SMP NEGERI 22 SEMARANG
}

\author{
Avella Itsna Fatimatuz Zahroh ${ }^{1}$, Endang Kurniati ${ }^{2}$, Ucik Fuadhiyah ${ }^{3}$ \\ 1,2,3 Jurusan Bahasa Jawa, Fakultas Bahasa dan Seni, Universitas Negeri Semarang, Indonesia \\ Corresponding Author: aitsna50@gmail.com ${ }^{1}$
}

\begin{abstract}
Abstrak
Penelitian mengenai pengembangan media komik pitutur luhur ini bertujuan untuk (1) menganalisis kebutuhan siswa dan guru terhadap media pembelajaran mituhu (komik pitutur luhur), (2) mendeskripsikan prototipe media pembelajaran mituhu (komik pitutur luhur), dan (3) mendeskripsikan hasil validasi ahli mengenai prototipe media pembelajaran mituhu (komik pitutur luhur). Desain penelitian ini adalah penelitian pengembangan. Prosedur penelitian ini meliputi (1) potensi dan masalah, (2) pengumpulan dan analisis data, (3) desain produk, (4) validasi desain, dan (5) revisi desain. Hasil penelitian menunjukkan beberapa hal, yaitu (1) guru dan siswa SMP Negeri 22 Semarang membutuhkan media pembelajaran menulis dialog berupa komik pitutur luhur, (2) komik pitutur luhur terdiri atas tiga cerita, yaitu cerita dengan judul Becik Ketitik Ala Ketara, Sapa Jujur Bakal Makmur, dan Aja Dumeh, (3) hasil validasi ahli materi mendapat nilai rata-rata 3,2 dari nilai maksimal 4 yang bermakna komik sesuai kompetensi dasar yang akan dicapai, hasil validasi ahli media mendapat nilai rata-rata 3,6 dari nilai maksimal 4 yang bermakna desain sesuai dengan kaidah pengembangan komik.
\end{abstract}

Kata Kunci: dialog, komik, media pembelajaran, menulis, pitutur luhur

\begin{abstract}
The objectives of this pitutur luhur comic strip study developement are (1) to analyze the needs of students and teachers towards mituhu learning media (pitutur luhur comics), (2) to describe prototypes of mituhu learning media (pitutur luhur comics), and (3) to describe the results of expert validation regarding mituhu learning media prototypes (pitutur luhur comics). The design of this research is research and development. The procedures of this study include (1) potential and problems, (2) data collection, (3) product design, (4) design validation, and (5) design revisions. The results of the study are (1) teachers and students of SMP N 22 Semarang need learning media to write dialogue in the form of pitutur luhur comics, (2) pitutur luhur comics consist of three stories namely Becik Ketitik Ala Ketara, Sapa Jujur Bakal Makmur, and Aja Dumeh, (3) the results of the material expert validation got an average value of 3.2 from a maximum value of 4 which means this comic according to the basic competencies to be achieved, the results of the media expert validation got an average value of 3.6 from a maximum value of 4 design meaningful in accordance with the rules of comic development.
\end{abstract}

Keywords: comics, dialogue, learning media, writing, pitutur luhur,

(C) 2020 Universitas Negeri Semarang

p-ISSN 2252-6307

e-ISSN 2714-867X 
Avella Itsna Fatimatuz Zahroh, dkk/ Piwulang 8 (1) (2020)

\section{PENDAHULUAN}

Bahasa Jawa sebagai pelajaran muatan lokal memuat empat aspek keterampilan berbahasa. Empat aspek keterampilan berbahasa itu meliputi menyimak, berbicara, membaca, dan menulis (Tarigan 1986:1). Sejalan dengan pendapat tersebut, Nursisto (2000:5) menyatakan bahwa menulis membutuhkan penguasaan materi sebagai modal dasar, seperti penguasaan kosakata, diksi, penyusunan kalimat, pemahaman secara aplikatif tentang ejaan dan tanda baca, logika, serta struktur berpikir yang runtut. Pembelajaran menulis khususnya menulis teks dialog terdapat pada Kurikulum 2013 dengan bunyi kompetensi dasar "menelaah dan menulis dialog sederhana" yang dipelajari siswa kelas VII. Pada kenyataannya keterampilan menulis dialog siswa kelas VII SMP Negeri 22 Semarang belum maksimal.

Berdasarkan hasil observasi di SMP Negeri 22 Semarang, siswa belum mampu memilih diksi yang tepat untuk menulis teks dialog. Hal ini dikarenakan kurangnya pengetahuan kosakata bahasa Jawa siswa. Selain itu, siswa masih keliru dalam menerapkan ragam bahasa Jawa. Faktor lain yang menghambat pembelajaran menulis dialog adalah kurangnya media pembelajaran menulis dialog. Menurut Sudjana dan Rivai (2009:2), media pengajaran dapat menarik perhatian siswa sehingga dapat menumbuhkan motivasi belajar. Sehubungan dengan pendapat tersebut maka media pembelajaran dapat digunakan untuk menumbuhkan motivasi belajar siswa dalam pembelajaran menulis dialog bahasa Jawa yang baik dan benar. Selain untuk mendidik siswa agar dapat berbahasa dengan baik, pelajaran bahasa Jawa juga harus dapat mendidik karakter siswa. Karakter siswa dapat dibentuk melalui pelajaran mengenai nilai-nilai kehidupan. Nilai tersebut terdapat pada pitutur warisan para leluhur atau bisa disebut pitutur luhur. Menurut (Sukirno, 2013:109), diterapkannya pitutur luhur dalam pembelajaran dapat membantu dalam pembentukan karakter. Memasukkan pitutur luhur dalam pembelajaran menulis dialog dapat dilakukan dengan mengembangkan media pembelajaran. Media pembelajaran menulis dialog yang memuat unsur pitutur luhur dapat menggunakan komik. Komik dapat dijadikan sebagai media dalam pembelajaran karena memiliki peranan yang dapat menunjang proses belajar mengajar. Peranan pokok dari komik dalam pembelajaran adalah kemampuannya dalam menciptakan minat siswa (Sudjana dan Rivai, 2009:68). Pengembangan komik pernah diteliti oleh Wiraswati (2015) dengan judul Komik Berdialek Tegal sebagai Media Pembelajaran Memahami Isi Teks Cerita Rakyat Kelas VII SMP. Wiraswati mengembangkan media pembelajaran berupa komik untuk materi memahami isi cerita rakyat. Komik yang dikembangkan menggunakan dialek Tegal dan memuat nilai-nilai sosial yang dapat dipelajari siswa. Penelitian lain juga pernah dilakukan oleh Aisyah, dkk (2017) dengan judul Learning Crude Oil by Using Scientific Literacy Comics. Aisyah, dkk mengembangan media pembelajaran untuk menumbuhkan literasi dalam pembelajaran sains.

Penelitian ini mengembangkan media pembelajaran menulis dialog dalam bentuk komik 
Avella Itsna Fatimatuz Zahroh, dkk/ Piwulang 8 (1) (2020)

pitutur luhur. Pengembangan ini diharapkan dapat menunjang kebutuhan siswa dalam pembelajaran menulis dialog serta sebagai sarana pendidikan karakter melalui pitutur luhur Jawa. Tujuan penelitian ini adalah (1) menganalisis kebutuhan siswa dan guru terhadap media pembelajaran komik pitutur luhur, (2) mendeskripsikan prototipe media pembelajaran komik pitutur luhur, dan (3) mendeskripsikan hasil validasi ahli mengenai prototipe media pembelajaran komik pitutur luhur.

\section{METODE PENELITIAN}

Desain penelitian ini adalah penelitian pengembangan (Research and Development). Menurut Sugiono (2015:298) prosedur penelitian pengembangan menggunakan sepuluh langkah, mengingat keterbatasan waktu dan biaya maka disederhanakan menjadi lima langkah diantaranya, (1) potensi dan masalah, (2) pengumpulan data, (3) desain produk, (4) validasi desain, dan (5) revisi desain. Data penelitian ini berupa kebutuhan siswa dan guru bahasa Jawa SMP Negeri 22 Semarang terhadap media pembelajaran menulis teks dialog. Adapun sumber data penelitian ini yaitu dari 64 siswa dan 2 guru SMP Negeri 22 Semarang.

Teknik yang digunakan untuk memperoleh data yaitu teknik observasi, teknik wawancara, dan teknik angket. Observasi merupakan langkah untuk dapat mengetahui permasalahan yang terjadi pada proses pembelajaran di sekolah. Pada lembar observasi berisi beberapa pertanyaan dan disesuaikan dengan keadaan pembelajaran yang ada.
Wawancara dilakukan dengan guru pengampu bahasa Jawa SMP Negeri 22 Semarang. Kemudian teknik angket digunakan untuk memproleh data dan bahan yang dibutuhkan untuk mengembangkan media pembelajaran bahasa Jawa yang benar-benar dibutuhkan oleh guru dan siswa. Angket yang digunakan meliputi angket kebutuhan dan angket penilaian. Angket kebutuhan ditujukan untuk siswa dan guru SMP Negeri 22 Semarang, sedangkan angket penilaian ditujukan kepada ahli untuk menilai validitas produk komik pitutur luhur.

Teknik analisis data yang akan digunakan dalam penelitian ini adalah deskriptif kualitatif, meliputi 1) mengidentifikasi kebutuhan media pembelajaran bahasa Jawa SMP kelas VII oleh siswa dan guru bahasa Jawa SMPN 22 Semarang berdasarkan angket yang telah disebarkan, 2) menyusun kebutuhan secara konkrit berdasarkan angket kebutuhan dan angket penilaian ahli sebagai dasar dalam mengembangkan media mituhu (komik pitutur luhur).

\section{HASIL DAN PEMBAHASAN}

Hasil penelitian ini meliputi analisis kebutuhan siswa dan guru, desain prototipe komik pitutur luhur, dan validasi ahli materi dan media terhadap prototipe komik pitutur luhur. Berikut penjelasan hasil penelitian.

Analisis Kebutuhan Siswa terhadap Komik Pitutur Luhur

Berdasarkan hasil jawaban dari 64 siswa SMP Negeri 22 Semarang, siswa membutuhkan media pembelajaran berupa komik bertokoh orang tua 
Avella Itsna Fatimatuz Zahroh, dkk/ Piwulang 8 (1) (2020)

dan anak dengan latar di lingkungan rumah. Kemudian untuk pertanyaan mengenai latar komik sendiri, siswa membutuhkan latar di sekolah, untuk itu tokoh guru dan siswa ditambahkan agar sesuai dengan kebutuan latar dalam komik. Penggunaan dialek pada komik yaitu dialek Semarangan karena siswa berasal dari daerah Semarang sehingga akan lebih mudah untuk memahami kalimat. Materi yang menjadi pilihan siswa yaitu materi mengenai pitutur luhur Jawa dengan cerita mengenai pendidikan dan sosial. Selain dari segi isi komik, pertanyaan pada angket juga mengacu pada desain yang diinginkan siswa. Jenis gambar yang dibutuhkan siswa yaitu gambar kartun dengan font Comic Sans MS. Siswa membutuhkan komik dengan warna full colour agar terlihat lebih menarik.

\section{Analisis Kebutuhan Guru terhadap Komik Pitutur Luhur}

Kebutuhan guru terhadap media pembelajaran komik pitutur luhur didapatkan dari hasil observasi, wawancara, dan angket kebutuhan guru. Berdasarkan hasil observasi didketahui bahwa media untuk menunjang pembelajaran menulis dialog siswa dalam bentuk bacaan masih kurang. Berdasarkan wawancara dengan guru diperoleh hasil berupa metode yang digunakan dalam pembelajaran dialog yaitu metode ceramah dan diskusi kelompok. Kendala yang dihadapi saat pembelajaran menulis dialog adalah kekeliruan penggunaan diksi yang dilakukan oleh siswa pada saat menulis dialog, penguasaan kosa kata yang masih kurang, dan media yang digunakan masih sebatas buku saja.
Sumber pemerolehan media berupa buku yaitu dari perpus sekolah, sehingga dibutuhkan media lain yang dapat menarik minat siswa sekaligus memberikan pengetahuan kosa kata agar dapat menulis dan berdialog dengan benar. Kemudian materi pembelajaran mengenai pitutur luhur belum ada.

Berdasarkan hasil angket kebutuhan, guru membutuhkan media komik karena melalui komik siswa dapat belajar diksi serta tanda baca yang benar. Pitutur luhur yang menjadi pilihan guru untuk dijadikan materi dalam komik yaitu sapa jujur uripe makmur, becik ketitik ala ketara, dan aja dumeh. Tema yang dibutuhkan guru dalam komik yaitu tema pendidikan dan sosial. Ragam bahasa dalam komik yaitu ragam ngoko dan krama dengan penggunaan sesuai dengan posisi pembicara. Dialek yang dibutuhkan guru dalam penyusunan komik adalah dialek Semarangan. Tokoh dalam komik, 1 guru memilih tokoh orang tua dan anak dengan alasan lebih cocok agar anak bisa lebih hormat dengan orang tua, dan 1 guru memilih lainnya yaitu semua bisa bergantung tema yang diangkat. Kemudian untuk latar dalam komik, guru memilih latar di sekolah, pasar, puskesmas, dan lingkungan rumah. Sesuai dengan kebutuhan siswa, maka latar yang dibutuhkan berada di sekolah, rumah, dan lingkungan masyarakat. Jenis gambar yang diinginkan guru adalah kartun dengan warna full colour. Ukuran komik adalah ukuran buku tulis dengan font Comic Sans MS. Guru membutuhkan komik dengan cerita sederhana dan tidak terlalu banyak agar siswa dapat mengerti amanat yang disampaikan melalui pitutur luhur tersebut. Guru 
Avella Itsna Fatimatuz Zahroh, dkk/ Piwulang 8 (1) (2020)

membutuhkan maksimal tiga cerita untuk menunjang pembelajaran menulis dialog.

\section{Desain Prototipe Komik Pitutur Luhur}

Berdasarkan hasil analisis kebutuhan siswa dan guru, disusunlah prototipe komik pitutur luhur. Penyusunan prototipe komik tersebut telah disesuaikan dengan pendapat Sitepu (2012:160) yang menyatakan bahwa isi komik umumnya sama dengan isi buku yang terdiri atas bagian awal, bagian isi, dan bagian belakang. Hanya saja bagian belakang komik tidak memuat glosarium, daftar pustaka, dan indeks karena tidak diperlukan. Bagian awal terdiri atas sampul, halaman judul, kata pengantar, dan daftar isi. Desain sampul depan berisi gambar tokoh utama yaitu Adit dan Gagah. Judul komik tersebut adalah Mituhu (Komik Pitutur Luhur) dengan font Kidzone ukuran 72. Bagian sampul belakang berisi panel setiap cerita yang ada pada komik. Halaman judul berisi nama penulis dan ilustrator. Kata pengantar berisi pengantar dari penulis, kemudian pada daftar isi terdapat bagian-bagian yang ada dalam komik beserta halamannya. Bagian isi terdapat kumpulan cerita berjumlah tiga buah dengan tema pitutur luhur.

Pitutur luhur yang dikembangkan yaitu becik ketitik ala ketara, sapa jujur bakal makmur, dan aja dumeh. Pitutur tersebut merupakan kebutuhan guru SMP Negeri 22 Semarang karena tema tersebut sangat baik untuk mendidik karakter siswa. Hal itu sesuai dengan Sigito (2014) yang menyatakan bahwa folklor becik ketitik ala ketara, sapa jujur bakal makmur, dan aja dumeh merupakan wewarah atau pitutur luhur atau wejangan (nasihat kearifan) yang dijadikan sarana mendidik atau nasihat untuk menanamkan nilai-nilai kepemimpinan, kebajikan, dan keteladanan dalam masyarakat Jawa. Tema tersebut kemudian dijadikan sebagai judul tiap cerita yaitu Becik Ketitik Ala Ketara, Sapa Jujur Bakal Makmur, dan Aja Dumeh. Cerita tersebut berisi nilai-nilai kehidupan seperti nilai kedisiplinan, kejujuran, dan kesederhanaan. Komik didesain full colour dengan warna cerah agar menarik dan sesuai dengan usia pembaca yaitu kelas VII SMP. Font yang digunakan pada bagian isi komik adalah Comic Sans MS dengan ukuran 11. Bagian akhir berisi biodata penulis. Biodata penulis berisi nama, tempat tanggal lahir, riwayat pendidikan, dan foto. Bagian akhir tidak menyertakan daftar pustaka, karena cerita yang ada di dalamnya adalah murni ide penulis. Komik tersebut disusun dengan ukuran buku A5 $(21 \mathrm{~cm} \times 15 \mathrm{~cm})$ dengan jumlah halaman sebanyak 52 termasuk bagian sampul buku.

\section{Hasil Uji Validasi Ahli terhadap Komik Pitutur} Luhur

Setelah proses penyusunan prototipe komik, kemudian dilakukan uji validasi materi dan media. Berdasarkan hasil validasi ahli materi, komik mendapat nilai rata-rata 3,2 dari nilai maksimal 4. Hasil tersebut bermakna materi sesuai dengan kompetensi dasar yang ingin dicapai, namun terdapat perbaikan dalam diksi diantaranya yaitu kata "mangkono" diganti "ngono", kata "mecahake" diganti "mecahaken", kata "takbayare" diganti "kula bayar", dan kata "tugase" diganti "tugasipun".

Berdasarkan hasil validasi ahli media, desain komik mendapat nilai rata-rata 3,6 dari 
Avella Itsna Fatimatuz Zahroh, dkk/ Piwulang 8 (1) (2020)

nilai maksimal 4. Hasil tersebut bermakna bahwa desain prototipe komik sudah sesuai dengan kaidah pengembangan komik dan sesuai untuk tingkatan pembaca yaitu kelas VII SMP. Terdapat saran perbaikan yaitu penyederhanaan warna balon kata. Warna balon kata sebelum diperbaiki terdiri atas merah, hijau, biru, kuning, dan putih sehingga mengganggu proses membaca. Warna balon kata kemudian disederhanakan menjadi dua warna saja yaitu putih dan kuning muda. Warna tersebut dipilih karena memiliki warna yang cerah sehingga menarik siswa untuk membaca.

\section{SIMPULAN}

Berdasarkan hasil penelitian tersebut, dapat disimpulkan bahwa responden membutuhkan komik pitutur luhur sebagai media pembelajaran menulis dialog. Hal ini dikarenakan kemampuan menulis dialog siswa yang masih kurang sesuai dengan kaidah penulisan yang tepat dan masih membutuhkan media pembelajaran yang bermuatan pendidikan karakter. Berdasarkan kebutuhan tersebut, maka disusunlah media pembelajan komik dengan tema pitutur luhur.

Komik ini berisi kumpulan cerita berjumlah tiga buah dengan tema pitutur luhur. Tema tersebut kemudian dijadikan sebagai judul tiap cerita yaitu Becik Ketitik Ala Ketara, Sapa Jujur Bakal Makmur, dan Aja Dumeh dengan bahasa Jawa dialek Semarangan. Cerita tersebut berisi nilai-nilai kehidupan seperti nilai kedisiplinan, kejujuran, dan kesederhanaan. Komik tersebut disusun dengan ukuran buku A5 $(21 \mathrm{~cm} \times 15 \mathrm{~cm})$, jenis huruf Comic Sans MS ukuran 11, dan dengan jumlah halaman sebanyak 52 termasuk bagian sampul buku.

Berdasarkan hasil validasi ahli materi, komik mendapat nilai rata-rata 3,2 dari nilai maksimal 4. Hasil tersebut bermakna materi sesuai dengan kompetensi dasar yang ingin dicapai. Kemudian hasil validasi ahli media, desain komik mendapat nilai rata-rata 3,6 dari nilai maksimal 4. Hasil tersebut bermakna bahwa desain prototipe komik sudah sesuai dengan kaidah pengembangan komik dan sesuai untuk tingkatan pembaca yaitu kelas VII SMP.

\section{DAFTAR PUSTAKA}

Aisyah, Riri, dkk. 2017. "Learning Crude Oil by Using Scientific Literacy Comics." Journal of Physics: Conf. Series 895. Bandung: UIN Sunan Gunung Djati. (diunduh pada 12 Juli 2018).

Nursisto. 2000. Penuntun Mengarang. Yogyakarta: Adicipta Karya Nusa.

Sigito, Sentot Prihandajani. 2014. Mikul Dhuwur Mendhem Jero. Malang: Universitas Brawijaya Press.

Sitepu, B.P. 2012. Penulisan Buku Teks Pelajaran. Bandung: PT Remaja Rosdakarya.

Sudjana, Nana dan Ahmad Rivai. 2009. Media Pengajaran (Penggunaan dan Pembuatannya). Bandung: Sinar Baru Algensindo.

Sugiyono. 2015. Metode Penelitian Kuantitatif, Kualitatif, dan R\&D. Bandung: Alfabeta.

Sukirno. 2013. "Pengkajian dan Pembelajaran Pitutur Luhur sebagai Pembentuk Karakter Peserta Didik". Jurnal 
Avella Itsna Fatimatuz Zahroh, dkk/ Piwulang 8 (1) (2020)

Pendidikan Karakter, Tahun III, Nomor

1. Purworejo: Universitas

Muhammadiyah Purworejo. (diunduh pada 3 April 2018).

Tarigan, Henry Guntur. 1986. Menulis Sebagai Keterampilan Berbahasa. Bandung: Angkasa.

Wiraswati, Windy Tri. 2015. Komik Berdialek Tegal sebagai Media Pembelajaran Memahami Isi Teks Cerita Rakyat Kelas VII SMP. Skripsi. Universitas Negeri Semarang. 